\title{
The Impact of Digital Transformation on the Economic Security of Ukraine
}

\author{
SERGIY SPIVAKOVSKYY ${ }^{1}$, OLEKSANDR KOCHUBEI ${ }^{2}$, OLENA SHEBANINA ${ }^{3}$, OLENA SOKHATSKA ${ }^{4}$, \\ IVAN YAROSHENKO ${ }^{5}$, TETIANA NYCH ${ }^{6}$ \\ ${ }^{1}$ Business Department, HIGHER COLLEGES OF TECHNOLOGY, UKRAINE. \\ ${ }^{2}$ Business-Economics and Tourism Department, KYIV NATIONAL UNIVERSITY OF TECHNOLOGY AND DESIGN, \\ UKRAINE. \\ ${ }^{3}$ Economic Cybernetics and Mathematical Modeling Department, MYKOLAIV NATIONAL AGRARIAN \\ UNIVERSITY, UKRAINE. \\ ${ }^{4}$ International Economic Relations Department, TERNOPIL NATIONAL ECONOMIC UNIVERSITY, UKRAINE. E-mail: \\ o.shebanina@gmail.com \\ ${ }^{5}$ Financial and Economic Security, Accounting and Audit Department, KHARKIV NATIONAL UNIVERSITY OF \\ MUNICIPAL ECONOMY NAMED AFTER BEKETOV, UKRAINE. \\ ${ }^{6}$ Economic and Social Geography Department, TARAS SHEVCHENKO NATIONAL UNIVERSITY OF KYIV UKRAINE, \\ UKRAINE.
}

\begin{abstract}
The article is devoted to the study of the impact of digital transformations on the economic security of Ukraine. The paper examines the essence of the digital economy, defines the features of the functioning of the economy in the context of digitalization. Based on the indicators of the international consulting company McKinsey and the World Bank, the authors analyzed the impact of digitalization on the economy, highlighted the main advantages and disadvantages of functioning in the digital economy, systematized the problems of economic security in the digital economy and highlighted systemic, structural and industry problems, as well as businesses and individuals. The main issues of economic security include the problems of "digital inequality", the lack of their element base, changes in the labour market, industrial espionage, manipulation of personal data and others. The authors also identified a tool for monitoring the development of a networked digital society - the Network Readiness Index. The practical contribution was the development of a mechanism to smooth the impact of digital transformation on the economic security of Ukraine.
\end{abstract}

Keywords: digital economy; digital transformation; economic security; informational security.

JEL Classification: E26, E32, F52 


\section{Introduction.}

The primary trend in the development of modern society is the digitalization of all its spheres. Modern information technology is an integral part of our life and continually influences various economic, social, technical and management systems (Robul et al., 2020; Sotnyk et al., 2020). Digitization processes play a vital role in the development of economic activity and the development of national economies and their security (Goncharenko and Sybachin, 2019; Trokhymets, 2019). As a result, the global trend of the world economy today is the formation and rapid development of the digital economy, which is characterized by the comprehensive and comprehensive implementation and application of new information technologies in all spheres of economic life without exception (Miśkiewicz, 2018). Against this background, one should not forget that digitalization processes, which are inevitable in their development, lead to positive changes in the functioning of all economic units without exception. On the other hand, there are negative consequences of using such methods. The devastating effects of digitalization for various social systems are primarily associated with the need to improve information security in society, introduce new measures to protect the safety of personal and corporate data and ensure the economic security of the country as a whole (Sean, 2014; Lukic and Živković, 2018; Helles and Flyverbom, 2019). Accordingly, under the influence of gradual digitalization, the transformation of methods and tools is vital to ensure not only knowledge but also the economic security of the country, since this type of protection is also directly related to the use of modern technologies for sustainable development, first of all, of business entities.

\section{Digitalization and its impact on the economy.}

The term "digital economy" was first introduced into economics in 1995 by Don Tapscott, who interpreted the concept as follows: "the digital economy is a type of economy based on the use of digital technologies" (Tapscott, 1995). In turn, the Department of Communications and the Digital Economy of Australia defines the digital economy as a global network of economic and social activities implemented through platforms such as the Internet, as well as mobile and touch networks (Apalkova, 2015; Shpak, 2020).

Researchers studying the prosperity impact of digitization have found measurable proxies for all six of these attributes (El-Darwiche et al., 2012). Thus, the level of digitalization can be assessed for any country.

Estimates show that the digitization process proceeds in four similar steps across all geographic regions (Fig. 1).

Over the past ten to fifteen years, several scientists and practitioners have analyzed the impact of the latest technology on the workplace. Scientists conclude that $47 \%$ of existing jobs in the United States are highly likely to become automated (where the probability is defined as $70 \%$ or higher) (Frey and Osborne, 2017). A recent PwC study (Berriman and Hawksworth, 2017) estimates that 38\% of U.S. jobs are at high risk of automation; the advanced economies are doing slightly better, with $35 \%$ of jobs at risk in Germany, 30\% in the U.K. and 21\% in Japan. The World Bank's 2016 World Development Report estimates that $57 \%$ of jobs in OECD countries could be automated in the next two decades (Berriman and Hawksworth, 2017). These studies paint an alarming picture, suggesting that between one third and half of existing jobs in advanced economies will be eliminated in a relatively short period.

The processes of digitalization received their most significant development in the economic spheres of society, as they had a considerable number of advantages for economic agents, primarily business entities. A study by the international consulting company McKinsey on the features and benefits of the digital economy shows that the digitalization of business processes affects the economic and social components, namely increasing productivity, including the number of jobs in related industries, accelerating the growth of the small and medium business, reducing the negative 
impact on the environment, the availability of online education, etc. (McKinsey Digital, 2020). Figure 1. Components of the Digitalization Score (El-Darwiche et al., 2012)

Figure 1. Components of the Digitalization Score (El-Darwiche et al., 2012)

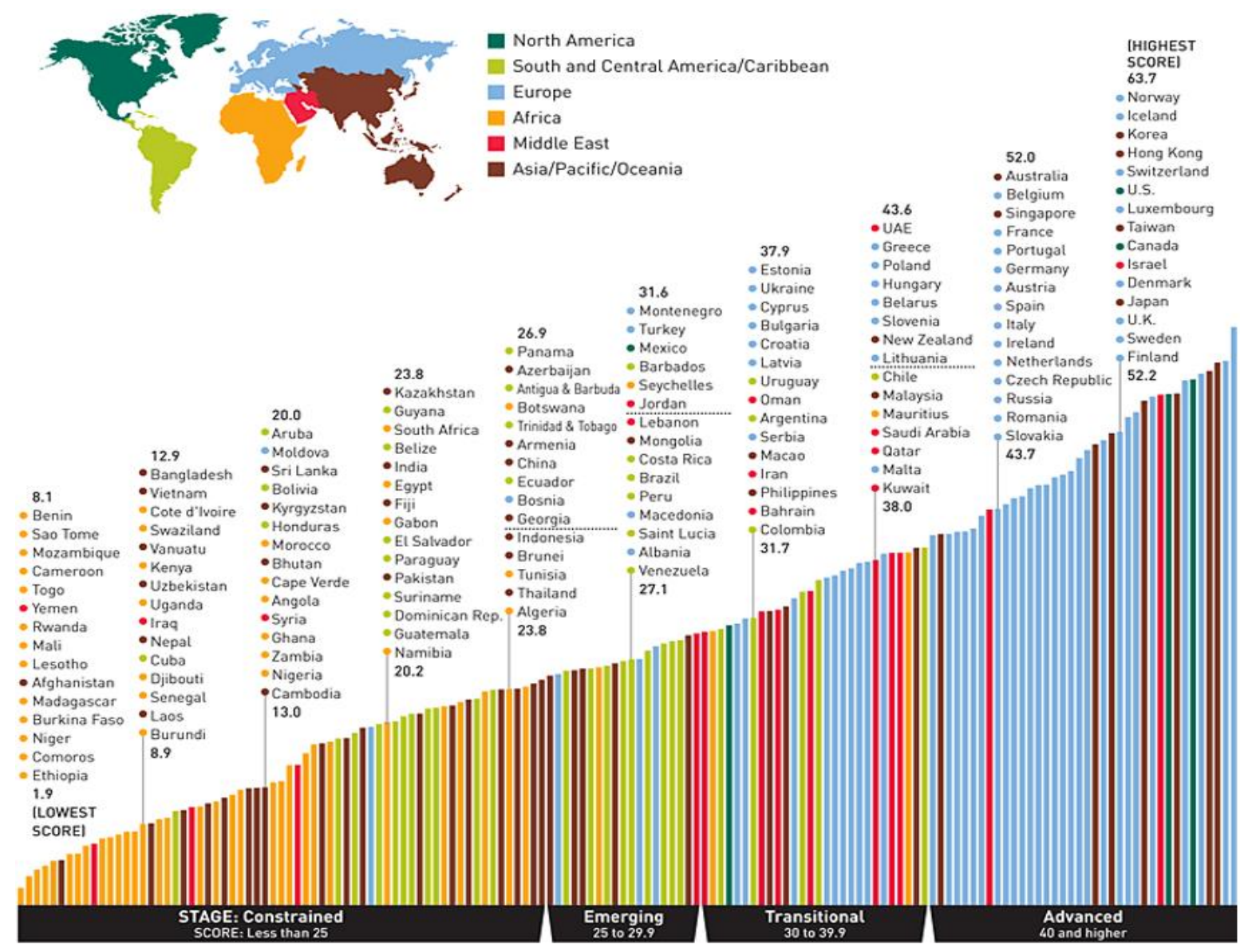

The development of the digital economy is an inevitable process and will become increasingly global in the future. Today, this type of economy is developing rapidly in the leading countries of the world, which actively support the processes of digitalization and form new national programs for the digitalization of society. According to analytical studies conducted by the World Bank, the International Bank for Reconstruction and Development and other companies, depending on the valuation methods, the size of the digital economy is currently estimated at 4.5 to $15.5 \%$ of world GDP. In the future, this share will increase (McKinsey Digital, 2020). The special attention of regulators around the world to the development of the digital economy, active support for the introduction of new technologies in the economic sphere is directly related to the significant opportunities of the digital world and the ability to improve the quality of life, increase financial capacity. In this regard, the DESI (The Digital Economy and Society Index) was developed to assess the level of technological development and the degree of the introduction of innovative technologies in society, including in the economic sphere. Fig. 2 provides information on the components of this index (communications, human capital, Internet use, integration of digital technologies and digital public services) and its significance for some developed countries. 
Figure 2. Digital Economy and Society Index, 2020 (DESI, 2020)

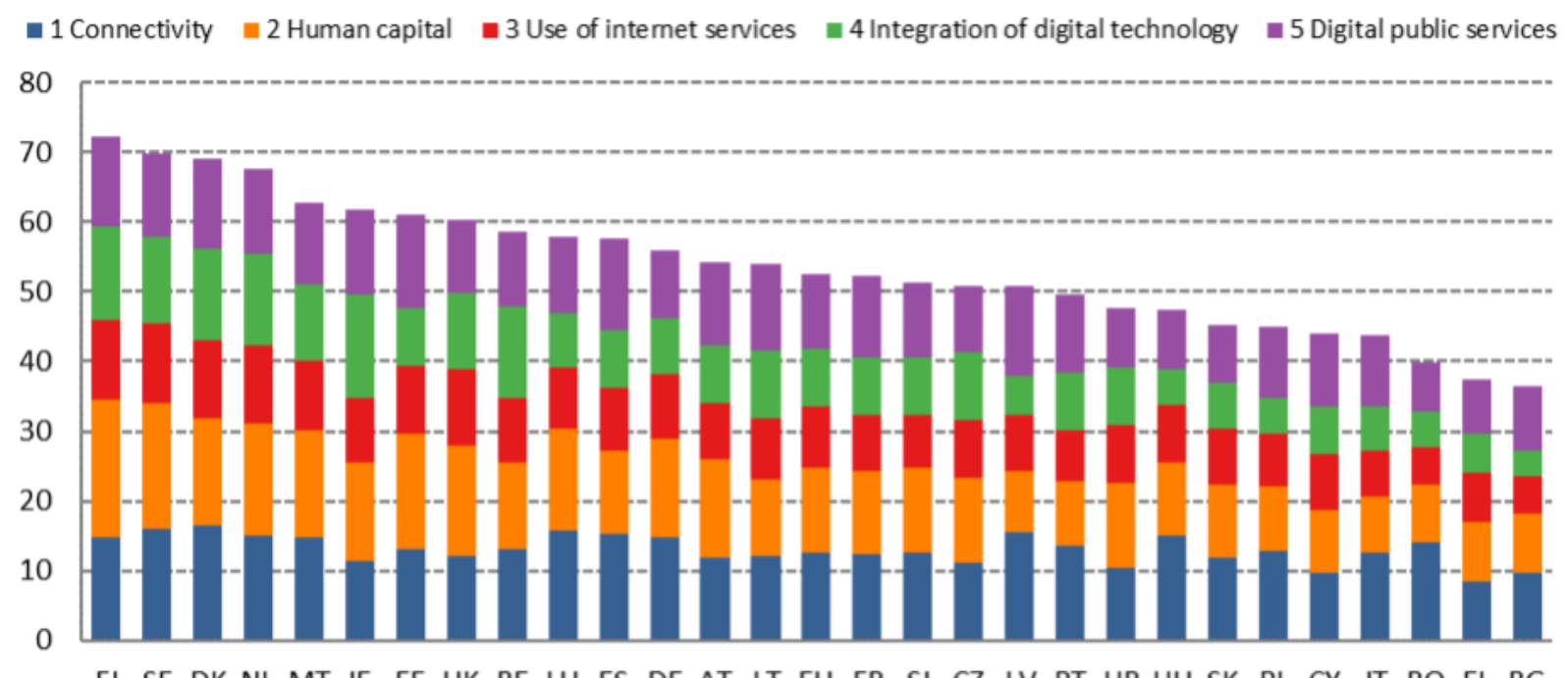

FI SE DK NL MT IE EE UK BE LU ES DE AT LT EU FR SI CZ LV PT HR HU SK PL CY IT RO EL BG

The development of the digital economy is directly related to the development and implementation of new information innovations in the work of individual business structures. In our country, the processes of digitalization have not become significant but arise and develop locally within separate economic entities. To accelerate the outlined processes, intensify the development of new information products, import of already formed technologies, it is an objective necessity to create the appropriate institutional support for the development of enterprises in the conditions of digitalization of society.

The main advantages of functioning in a digital economy are:

- use of computer technology, software and hardware;

- introduction of innovations in business processes;

- operation of large arrays of information data;

- ensuring information protection;

- the inflow of new investments;

- increase labour productivity;

- customer focus;

- speed and efficiency of any functions, etc.

However, as already noted, along with the development of the digital economy, there are also new threats that can have a destructive impact on Ukraine's economic security. Thus, along with the adaptation of economic activity to the requirements of the digital economy, the government should pay considerable attention to the creation of effective information security systems. This, in turn, requires significant financial resources. Accordingly, the issue of ensuring the sustainability of the economic security system as an integral part of the stable development of economic entities needs attention.

\section{Digital threats significantly affecting economic security and tools for their solution.}

Analysis of the literature makes it possible to systematize digital threats and challenges that significantly affect economic security into at least three groups (Table 1 ). 
Table 1. Problems of economic security of a digital society

\begin{tabular}{|c|l|}
\hline Type of problem & \multicolumn{1}{c|}{ Description } \\
\hline Systemic & $\begin{array}{l}\text { Problems related to the economy or its significant parts (dependence on } \\
\text { digital technologies of other states, lack of own element base, the question of } \\
\text { "digital inequality") }\end{array}$ \\
\hline Structural & $\begin{array}{l}\text { Structural problems caused by digitalization (for example, significant changes } \\
\text { in the labour market and rising unemployment). }\end{array}$ \\
\hline Industry & $\begin{array}{l}\text { Lack of digital solutions for specific industries (for example, lack of their } \\
\text { payment system) }\end{array}$ \\
\hline $\begin{array}{c}\text { Activities of } \\
\text { individual } \\
\text { enterprises }\end{array}$ & $\begin{array}{l}\text { Theft of corporate data, industrial espionage, hacker attacks, insufficient } \\
\text { provision of digital technologies, competent personnel, etc. }\end{array}$ \\
\hline Individual citizens & Theft, manipulation of personal data \\
\hline
\end{tabular}

The fundamental response to these challenges of the digital society is changes in the structure and approaches to the management of economic systems at different levels. Horizontal teams aimed at obtaining results come to the fore in such changes. This requires a shift from closed, overly bureaucratic structures to open organizations that create a network. Such organizations are hybrid forms of economic activity with flexible connections that are established and revised as necessary. The most critical issues in such network structures are the issues of real-time resource management and coordination of network members. As part of the development of the "partial economy", this approach is implemented through digital platforms, through which participants can coordinate to use resources more efficiently (for example, sharing housing, car, etc.). Such tools allow more efficient use of resources, increasing their availability, reducing the burden on the environment. In modern enterprises, such problems are solved with the help of digital economy tools, such as "cloud" technologies, ERP-systems and several other instruments. With the development of network structures in the economy will be a noticeable transformation of the industrial economy, the creation of a flexible network of new structures and new forms of organizations of production and economic activity. The economic advantages of network forms are their ability to adapt quickly to changing conditions. Because the boundaries of networked forms of organization are usually easier to manage than the limitations of hierarchies, it is easier to modify the composition of networked organizations in response to these changes. The results of such development will be an increase in the number of small-scale production, individual fulfilment of production orders. The changes will affect other aspects of the economy, including the labour market. Now the main requirements of the employer to employees are the ability to work in a team, work in a multitasking mode, a creative approach to solving problems, a high degree of adaptation to rapidly changing conditions, which is typical for network organizations. In general, there is an intellectualization of labour and capital, the growth of the information capacity of the modern economy.

The primary tool for monitoring the development of network phenomena in the economy is the Network Readiness Index (NRI) - a comprehensive indicator proposed by the World Economic Forum and the International School of Business "INSEAD". Currently, this index is considered the most complete and authoritative source of the international assessment of the impact of post-industrial development factors on the competitiveness and welfare of countries. It is used as a tool for analysis to build comparative ratings that reflect the level of development of the components of the network economy, and includes the following sub-indices:

1. environmental development;

2. society's readiness to use digital technologies;

3. the actual use of digital technologies by primary economic agents;

4. the effects that digital technologies have on the economy and society.

The first three sub-indices can be considered as a driver that determines the value of the fourth sub-index, i.e. the impact of digital technology on society and the economy. The development of a 
network economy requires, above all, appropriate market conditions, public administration and regulatory framework that create the environment. Assessment of the business and innovation environment determines the quality of business conditions. According to the 2019 study, Ukraine is in 67th place out of 121 in terms of network readiness (Fig. 3).

Figure 3. Ranking Countries (Network Readiness Index, 2019)

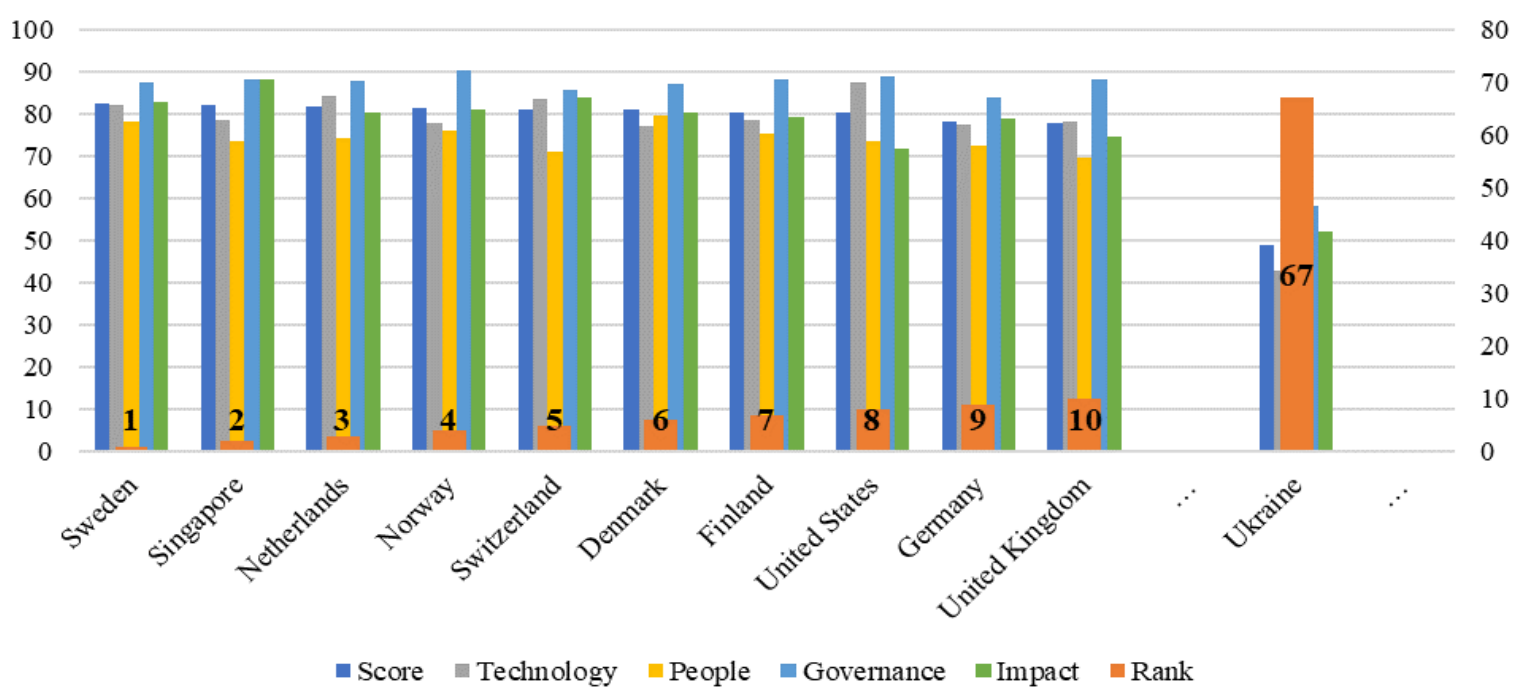

The country's readiness for the network economy largely depends on the extent to which the primary agents of the economy are interested and prepared to use network technologies in their daily activities. It is assessed by the availability of network infrastructure and access to digital information, the cost of network connections and the level of competition in this area, the ability of society to effectively use digital technologies through the availability of necessary educational skills (Gumennykova et al., 2020).

The formation of a network structure based on a highly developed information and management infrastructure and the effective use of intellectual resources involves a significant change in the entire socio-economic system of society and the state. Network technologies occupy a central place in the renewal of critical areas of society: public and municipal government, business, education, environment, health, culture, security, public life (Pohrebennyk et al., 2017; Barchan et al., 2020; Demikhov et al., 2020). The network component of economic relations ensures the efficiency of individual economic agents, reduces transaction costs and establish a mobile organization of work. We can say that without solving the problems of their effective large-scale use, without the development of network infrastructure today, it is impossible to solve any of the priority tasks of socio-economic development successfully. An essential change in the approach to management in current conditions is a fundamentally different attitude to man and his role in decision-making. With the development of the digital economy, the place and role of man in a new type of management are changing significantly.

Analysis of such changes includes the study of a range of interrelated issues: changing labour requirements, the transformation of the education and training system, new approaches to the management system (Prokopenko et al., 2014). The level of knowledge, competencies and skills of the population in the field of digital technologies is an essential factor in the spread and development of these trends in various spheres of public life. The category "human capital" is used to analyze this factor of socio-economic development. In the conditions of formation of digital economy interpretation of this concept expands, thus more significant role is given to skills in the field of digital technologies. Improving the quality of human capital, involving more and more people in educational processes, developing skills and competencies in the field of digital technologies is the basis for the formation of the digital economy and the effective use of digital technologies in various 
areas. Changes in the demand for skills pose two severe challenges to the education and training system.

First, despite the recognition that the demand for skills in the future will be significantly different from today, it is difficult to identify and predict due to rapid technological change. Second, the problem of adapting the skills development system to new conditions after the demand for skills has changed. Several countries are currently developing digital skills development strategies to help countries build their strengths and mitigate the shortcomings of their national education systems.

The determining factor in the development of a new type of society and its inherent economy is the dominant role of highly skilled creative work. Economic efficiency in current conditions is determined not so much by quantitative indicators of the number of staff, but by the presence of specialists who can create a new product or offer a new service, find a new way of organizing production, respond adequately to changing market conditions. New forms of human activity appear; human capital is dynamically formed, which is expressed in updated knowledge and skills continuously. Continuing education and advanced training are becoming a necessary condition for the development of the modern economy. Currently, there is a tendency to increase the average period of education. This is facilitated by the fact that continuous professional development is the key to social success and stable income.

\section{Research results: smoothing the impact of digital transformation on the economic security of} Ukraine.

We believe that only systematicity and sustainability will be able to effectively smooth the impact of digital change on Ukraine's economic security. When developing a solution, it is necessary to adhere to generally accepted principles, which include the following:

- consistency - this principle means that good architecture is consistent when partial knowledge of the system allows you to predict otherwise;

- orthogonality - this principle requires that the functions be independent of each other and specified separately;

- compliance - means that the architecture should include only those functions that meet the essential requirements of the system;

- cost-effectiveness - no part in the description of architecture should in any way duplicate another;

- transparency - the user must know the functions found during the execution;

- commonality - the function that is reintroduced should be introduced in such a way that it corresponds to as many purposes as possible;

- openness - the user should be able to clarify the specification and content of system functions in the process of its use;

- completeness - the specification of functions must meet all the requirements and wishes of the user.

We propose a mechanism for smoothing the impact of digital transformation on the economic security of Ukraine, which would meet these criteria and take into account security-oriented strategic management (industry) (Fig. 4).

Of course, in practice, everything may not go so smoothly:

- substages may not take place in such order; they may break, jump, obey the feedback, overlap, parallel motion;

- the decision-making process is all the more individual than the decision is more complicated;

- limited amount of information limits the rationality of the decision, the growing role of intuition; 
- previous settings for alternatives affect the choice of the solution;

- there is no desire for the optimal solution if something is satisfying;

- managers of different levels of management in various ways interfere in the structure and decision-making process, thus affecting their quality.

The key to the successful implementation of the mechanism is the effective distribution of responsibilities and decision-making powers.

\section{Conclusion.}

Figure 4. The proposed mechanism for smoothing the impact of digital transformation on the economic security of Ukraine

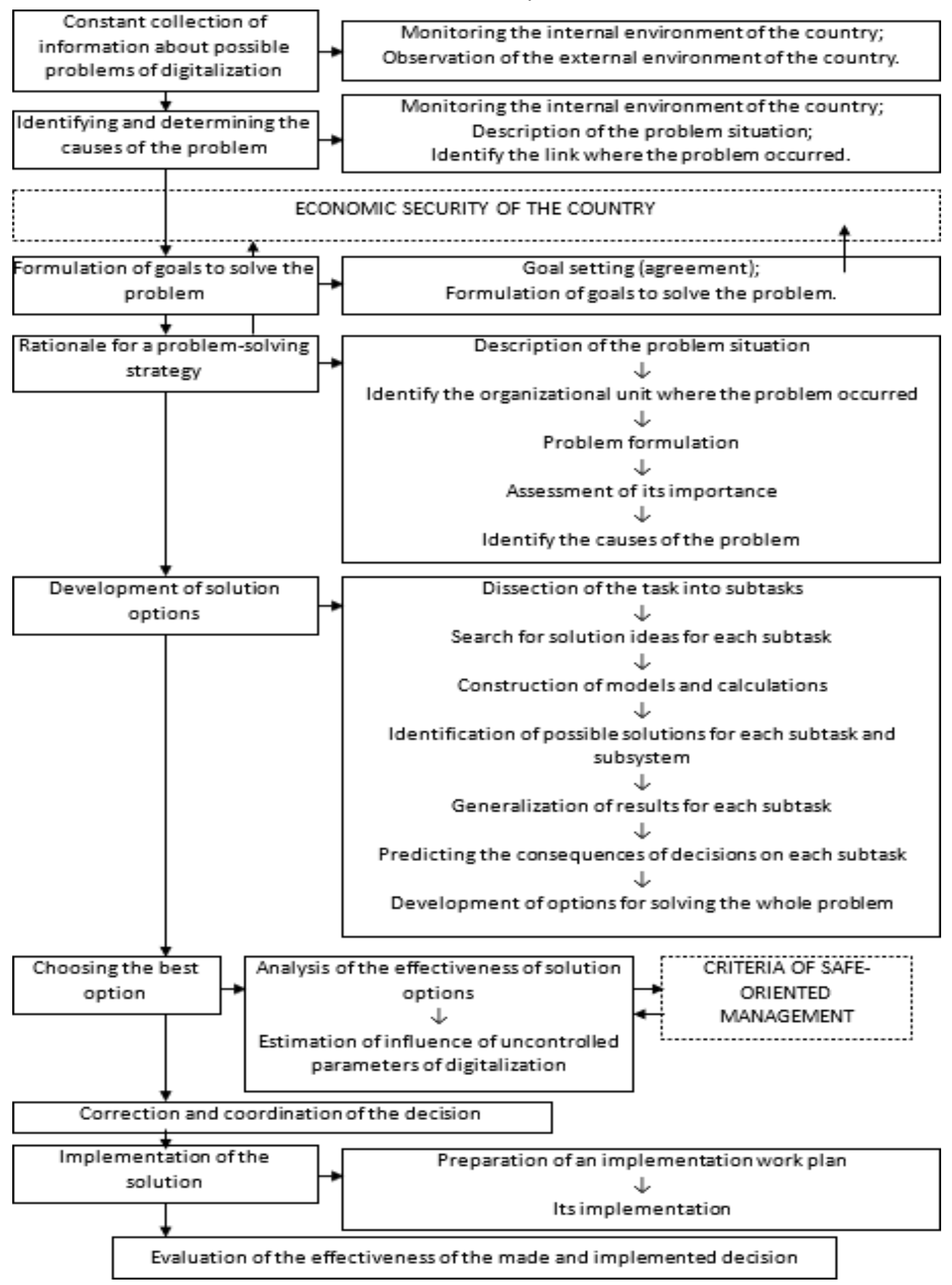


Thus, modern society is gradually moving to the digital stage of its development. Digitalization has already become an integral part of the functioning of various social systems. Digitization processes have a significant impact on the development of national economies around the world. Accordingly, given the effects of such operations, the behaviour of economic agents, especially businesses, changes.

As a result of the conducted research for systematization of problems of maintenance of economic safety in the conditions of development of global digitalization, the following results are received:

First, the authors show that anticipating the challenges and threats of globalization is a priority for economic security, especially in today's rapidly changing global world.

Secondly, the problems of economic security in the digital economy are systematized, systemic, structural and branch problems, as well as enterprises and individual citizens, are singled out. The main issues of economic security include the issues of "digital inequality", the lack of its elemental base, changes in the labour market, industrial espionage, manipulation of personal data and others.

Third, the tools for solving the problems of the digital society are identified, which include digital platforms for the development of the "shared economy", as well as "cloud" technologies and methods of processing large databases. A network readiness index is a tool for monitoring the development of the digital network society.

Fourth, the issues of using appropriate software and hardware, software, attracting highly qualified personnel to create reliable protection of work from exogenous destructive factors of digitalization are becoming relevant.

Fifth, the authors proposed the development of a mechanism to smooth the impact of digital transformation on the economic security of Ukraine.

A large-scale solution to the problems of economic security of the digital society will ensure the purposeful formation of the process of economic growth and increase the economic well-being of the whole society.

\section{References}

1. Apalkova, V. (2015). Concept of Digital Economy Development in E.U. and Prospects of Ukraine. Bulletin of Dnipropetrovsk University. Series: Innovation Management, 4, pp. 9-18.

2. Barchan, G., Demikhov, O., Cherkashyna, L. Shklyar, A., Dehtyarova, I., \& Demikhova, N. (2020). A complex of regional ecological and medico-social factors: evaluation of dysplastic dependent pathology of the bronchopulmonary system. Polski merkuriusz lekarski, 283, pp. 49-54.

3. Berriman R., \& Hawksworth J. (2017). Will robots steal our jobs? The potential impact of automation on the U.K. and other major economies. U.K. Economic Outlook, pp. 30-47.

4. Demikhov O., Dehtyarova I., \& Demikhova N. (2020). Actual aspects of public health policy formation on the example of Ukraine. Bangladesh Journal of Medical Science, vol. 19 (3), pp. 35836. DOI: $10.3329 /$ bjms.v19i3.45850

5. Digital Economy and Society Index (DESI) (2020). https://ec.europa.eu/digital-single-market/desi

6. El-Darwiche, B., Singh, M., \& Ganediwalla, S. (2012). Digitization and Prosperity. The economic growth of nations is linked to one factor: adoption of information and communications technology. World View, 68. https://www.strategy-business.com/article/00127?gko=b781c

7. Frey, C.B., \& Osborne, M. (2017). The future of employment: How susceptible are jobs to computerization? Technological Forecasting and Social Change, 114, pp. 254-280.

8. Goncharenko L.P., \& Sybachin S.A. (2019). Digitalization of national economy. Vestnik Universiteta, 8, pp. 32-38. DOI: 10.26425/1816-4277-2019-8-32-38

9. Gumennykova, T., Pankovets, V., Liapa, M., Miziuk, V., Gramatyk, N., \& Drahiieva, L. (2020). Applying instructional design methods to improve the effectiveness of blended-learning. International Journal of Management, 11(5), pp. 31-42. 
10.Helles, R., \& Flyverbom, M. (2019). Meshes of Surveillance, Prediction, and Infrastructure: On the Cultural and Commercial Consequences of Digital Platforms. Surveillance \& Society, 17(1/2), pp. 34-39, DOI: $10.24908 /$ ss.v17i1/2.13120

11.Lukic, V., \& Živković, A. (2018). The consequences of digital revolution in monetary realm, DOI: 10.5937/AnEkSub1839157L

12.McKinsey Digital (2020). https://www.mckinsey.com/business-functions/mckinsey-digital/ourinsights

13.Miśkiewicz, R. (2018). The importance of knowledge transfer on the energy market. Polityka Energetyczna, 21(2), 49-62. http://dx.doi.org/10.24425\%2F122774

14. Network Readiness Index. Benchmarking the Future of the Network Economy. https://networkreadinessindex.org/

15.Pohrebennyk, V., Korostynska, O., Mason, A., \& Cygnar, M. (2017). Operative Control Parameters of Water Environment. Proceedings - 2016, 9th International Conference on Developments in eSystems Engineering, DeSE 2016, № 7930669, pp. 335-340.

16.Prokopenko, O.V., Domashenko, M.D., \& Shkola, V.Y. (2014). Management features of economic security in foreign economic activity of ukrainian machine-building enterprises. Actual Problems of Economics, 160(1), pp. 188-194.

17.Robul, Y., Deineha, O., Prokopenko, M., Novikova, N., Lukianykhina, O., \& Baistriuchenko, N. (2020). Cyber sales as the latest tool for optimizing an enterprise strategy. International Journal of Scientific and Technology Research, 9(2), pp. 5264-5268. http://www.ijstr.org/finalprint/feb2020/Cyber-Sales-As-The-Latest-Tool-For-Optimizing-An-Enterprise-Strategy.pdf

18.Sean, B. (2014). Victims of Success: Managing the Consequences of Digital Outreach. The Primary Source, 33(2), DOI: 10.18785/ps.3302.03

19.Shpak, N., Kuzmin, O., Dvulit, Z., Onysenko, T., \& Sroka, W. (2020). Digitalization of the Marketing Activities of Enterprises: Case Study. Information, 11, 109. https://doi.org/10.3390/info11020109.

20.Sotnyk, I., Hulak, D., Yakushev, O., Yakusheva, O., Prokopenko, O.V., \& Yevdokymov, A. (2020). Development of the U.S. electric car market: Macroeconomic determinants and forecasts. Polityka Energetyczna, 23(3), pp. 147-164. DOI: https://doi.org/10.33223/epj/127921

21.Tapscott, D. (1995). The Digital Economy: Promise and Peril in the Age of Networked Intelligence. McGraw-Hill, 342 p.

22.Trokhymets, O. (2019). Development of national economy in the context of information and digitalization processes. In book: Challenges and prospects for the development of a new economy at global, national, and regional levels. DOI: 10.36059/978-966-397-147-6/111-128 